Bond University

Research Repository

\title{
Psychological Determinants of Continued Obesity One-Year Postbariatric Surgery
}

Stapleton, Peta; Spinks, Teagan; Carter, Brett

Published in:

Psychological Reports

DOI:

$10.1177 / 0033294119844983$

Licence:

Other

Link to output in Bond University research repository.

Recommended citation(APA):

Stapleton, P., Spinks, T., \& Carter, B. (2020). Psychological Determinants of Continued Obesity One-Year

Postbariatric Surgery. Psychological Reports, 123(4), 1044-1063. https://doi.org/10.1177/0033294119844983

\section{General rights}

Copyright and moral rights for the publications made accessible in the public portal are retained by the authors and/or other copyright owners and it is a condition of accessing publications that users recognise and abide by the legal requirements associated with these rights.

For more information, or if you believe that this document breaches copyright, please contact the Bond University research repository coordinator. 
Psychological Determinants of Continued Obesity One-Year Post-Bariatric Surgery

Peta Stapleton, PhD 1*, Teagan Spinks MClinPsyc 1, and Brett Carter, BPsyc 1 1 School of Psychology, Bond University, Queensland Australia 4229

*Address correspondence to this author at School of Psychology, Bond University, Gold Coast, Queensland, 4229, Australia.

Telephone: +61 755952 515, Facsimile: +61 755952 540, pstaplet@,bond.edu.au 
Psychological Determinants of Continued Obesity One-Year Post-Bariatric Surgery 


\begin{abstract}
Objective: Bariatric surgery is an effective treatment for obesity, however, an estimated $20 \%$ of patients do not experience significant weight loss post-surgery. The current study examined the interaction of potential psychological factors and their mediating effects on the emotional eating (EE) of individuals one-year post bariatric surgery. Method: Three-hundred and sixty-six obese individuals (348 females; 95.1\%) with a Body Mass Index (BMI) greater than 30 $\mathrm{kg} / \mathrm{m} 2(M=39.14 ; S D=7.67)$ completed the Patient Health Questionnaire (PHQ), the Brief COPE, the Big-Five Mini-Marker of Personality, and the Three-Factor Eating Questionnaire (TFEQ-R-18). Results: The variance accounted for in EE by age and twelve psychological factors were assessed via a four-step hierarchical multiple regression. Avoidant coping and the personality traits of extraversion, agreeableness, and in contrast to that hypothesised, emotional stability were significant predictors of emotional eating. Avoidant coping partially mediated the relationships of extraversion and emotional stability with EE and fully mediated the relationship of agreeableness. Conclusion: Certain personality traits may influence the preferred coping style chosen by individuals who experience continued obesity after bariatric surgery. Additional supports and tailored interventions that are matched with the needs of this population may subsequently be necessary to overcome EE and improve weight loss.
\end{abstract}

Keywords: bariatric, coping, emotional eating, obesity, personality, psychosocial 
Psychological Determinants of Continued Obesity One-Year Post-Bariatric Surgery

Obese individuals who undertake bariatric surgery have shown 50 to $60 \%$ excess body weight reductions and substantial improvements in obesity-related conditions such as metabolic syndrome, type 2 diabetes, hypertension, and adjusted long-term mortality (Abilés et al., 2010; Dixon et al., 2008; Sjöström, Lissner, Wedel, \& Sjöström, 1999). The surgery is also likely to result in associated positive psychological outcomes such as decreased psychopathology, depressive and anxious symptoms, improved eating behaviour, body image, and self-esteem (Bocchieri, Meana, \& Fisher, 2002; Herpertz, Kielmann, Wolf, Langkafel, Senf, \& Hebebrand, 2003). Whilst a larger proportion of surgery patients' outcomes are positive, approximately $20 \%$ of patients do not experience significant weight loss (Abilés et al.). It is suggested this effect is likely caused by underlying psychological factors, rather than complications or failure of the surgical procedure undertaken (e.g. postsurgical gastric dilatation; Busetto et al., 2005), that can promote over-consumption of food and propagate continued obesity (Fischer et al, 2007).

\section{Emotional Eating}

Research has identified emotional eating (EE) as a risk factor for overconsumption of food, and consequently, obesity (Fischer et al, 2007). EE refers to the tendency to consume food in response to negative emotional states (van Strein, Engels, van Leeuwe, \& Snoeck, 2005) which has been demonstrated as a factor related to obesity in bariatric populations (Goodspeed Grant, 2008). Studies investigating the biology behind EE indicate the behaviour is counterintuitive due to the hormonal and gastric changes leading to appetite suppression in response to negative affective states (Blair, Wing, \& Wald, 1991; Wing, Blair, Epstein, \& McDermott, 1990). This effect, however, has been observed across populations and studies including both healthy weight and overweight or obese individuals (Geliebter \& Aversa, 2003). 
Consumption of foods, particularly those high in sugar and fats, can be biological reinforced through activation of the dopamine reward pathway (Bruinsma \& Taren, 1999). Thus, food choices have been found to be affected by biological drives for pleasure seeking as improvements in mood states have been observed after such foods (Bruinsma \& Taren; Macht \& Muller, 2007). Obese individuals have shown higher rates of EE and a greater amount of food consumed than healthy weight counterparts (Fischer et al, 2007; Ganley, 1989; Gelibter \& Aversa, 2003). From a psychological perspective it has been proposed when an individual experiences distress EE may be used as a coping mechanism (Kaplan \& Kaplan, 1957; NguyenRodriguez, Unger \& Spruijy-Metz, 2009). Affect, both positive and negative, may also serve as temporary disinhibitors of cognitive restraint, which lead to over-consumption via EE (Herman \& Mack, 1975; Herman \& Polivy, 1980; Macht \& Muller, 2007).

\section{Psychological Factors and Emotional Eating}

Psychological symptoms for depression, anxiety, and somatisation, tend to co-occur in the overweight population and can have a significant impact on weight-loss success and psychological well-being (Goossens, Braet, Van Vlierberghe, \& Mels, 2008; Kottinen, Mannisto, Sarlio-Lahteenkorva, Silventoinen, \& Haukkala, 2010; Ouwens, van Strien, \& van Leeuwe, 2009). Depression symptomology has been consistently found as predictive of increased EE. (Karlsson et al., 2000; Konttinen et al.; Ouwens et al.). For patients of gastric banding/bypass, a lifetime diagnosis of an anxious disorder may result in significantly less weight loss than those who are non-anxious (de Zwaan, et al., 2011), and trait anxiety may be useful for predicting EE in obese, but not lean, participants (Schneider et al., 2010). Another important consideration is the influence that enduring and relatively stable personality traits may have on EE, obesity, and bariatric surgery outcomes (Magee \& Heaven, 2011; Provencher et al., 2008). 
Increased levels of the Big-Five personality traits (Costa \& McCrae, 1992) of extraversion, agreeableness and neuroticism (opposed to emotional stability) have been positively associated with obesity, and conscientiousness inversely (Magee \& Heaven, 2011). Extraversion was also found to be predictive of weight gain in the same sample at two-year follow up. Systematic review has supported the positive associations of high neuroticism and low conscientiousness with increased weight, but only found extraversion a risk factor for men, and inconclusive findings for agreeableness (Gerlach et al., 2013; Jokela et al., 2013; Magee \& Heaven, 2011). Given the mixed findings, further investigation is required to examine the effects of personality traits on $\mathrm{EE}$, and consequently, obesity, in a post-bariatric surgery population. According to the cognitive-phenomenological theory of psychological distress (Lazarus, 1966), personality traits may also influence and interact with how post bariatric surgery patients might appraise their situation and employ a coping style.

Those who elect for bariatric surgery may be more likely to use an emotional coping rather than problem-oriented approach (Ryden et al., 2001). Avoidant coping, an emotional variant, is considered for the most part maladaptive. It has been reliably associated with higher neuroticism (Carver, Scheier, \& Weintraub, 1989; Moser, Prelow, Chen, \& Yackel, 2006) and $\mathrm{EE}$ in formerly obese individuals attending weight management and relapse prevention (Byrne, 2002). In contrast, bariatric patients who use active coping, a problem-oriented approach, may be more likely to experience higher percentages of weight loss (Ahnis et al., 2015; Figura et al., 2015) and possess more positive and optimistic personality traits (Mosher et al., 2006). Although assessing coping styles in bariatric patients may be limited by the proposal that 'delegated' problem-oriented coping is required to satisfy the extensive measures for bariatric surgery (Ahnis et al.), the relationship with EE post-surgery is important to consider. In particular there is 
evidence to suggest coping styles may have mediating effects on EE outcomes, as witnessed previously between both supportive and unsupportive social interactions and EE (Raspopow, Matheson, Abizaid, \& Anisman, 2013).

\section{The Present Study}

Whilst there is evidence investigating the potential psychological factors impacting on immediate post-bariatric surgery weight loss success, little evidence has been gathered in relation to factors for those individuals who do not experience this desired outcome. The aim of this study was to investigate the potential influence and mediating effects of psychological disorder symptomology, personality traits, and coping styles on the EE behaviour of a population that was at least one year post-bariatric surgery, and who continued to have a BMI in the obese range. Psychological symptoms (depression, anxiety, somatization), avoidant coping, and the personality traits of extraversion and agreeableness were hypothesised to be significant individual positive predictors of increased EE behaviours. The inverse was hypothesised for positive reframing, active, and support coping styles and the personality traits of conscientiousness, openness to experience, and emotional stability. Finally, it was believed avoidant coping would mediate the relationships between emotional stability, extraversion, and agreeableness with EE.

\section{Method}

\section{Participants}

All 366 participants $\left(M_{\text {age }}=46.17 ; S D=10.09\right.$; range $21-76$ years $)$ had a BMI $>30$ $\mathrm{kg} / \mathrm{m} 2(M=39.14 ; S D=7.67)$ and were at least one year post-bariatric surgery. The predominantly female sample $(349 ; 95.1 \%)$ were recruited from national and international weight-related (e.g., Obesity Help) and social networking sites (e.g. Facebook) using purposive 
and convenience sampling methods, respectively. Given the recruiting method there was insufficient information made available to conduct a responders' analysis to determine any potential bias between responders and non-responders.

\section{Design and Procedure}

Ethical approval was obtained from the Bond University Human Research Ethics Committee and approved by the Australian and New Zealand Clinical Trial Registry. Potential participants were provided with an online link directing them to an explanatory statement and consent form on PsychData. After consent was obtained, participants were asked to complete demographic items and four psychometric instruments. Each instrument was presented on a separate page and all items were forced-response questions. The anonymous questionnaire package took approximately 30-40 minutes to complete.

\section{Measures}

Four surveys were administered to participants, those being the: Patient Health Questionnaire (PHQ; Kroenke, Spitzer, Williams, \& Löwe, 2010); Brief COPE (Carver, 1997); Big-Five Mini-Marker of Personality (BFMM; Saucier, 1994); and Three Factor Eating Questionnaire R-18 (TFEQ-R18; Karlsson, Persson, Sjöström, \& Sullivan, 2000).

The PHQ is a self-report measure aiding in provisional diagnosis of a range of disorders including depression, anxiety, and somatic distress (Kroenke et al., 2010). The depression scale is composed of nine items aligning with diagnostic criteria in the DSM-IV for Major Depressive Disorder. Items are scored 1 (not at all), 2 (several days), 3 (more than half the days), and 4 (nearly every day). An answer of 3 or 4 to either or both of the items 'little interest or pleasure in doing things' or 'feeling down, depressed, or hopeless', with an additional five items (e.g. 'feeling tired or having little energy') meets the provisional diagnostic criteria for depression. 
The seven anxiety scale items relating to general anxiety symptoms were scored 0 (not at all), 1 (several days), and 2 (more than half the days). Criteria was met if the person answered 2 to the item 'feeling nervous, anxious, on edge, or 'worrying a lot about different things', and an additional three items (e.g. 'feeling restless so that it is hard to sit still'). Thirteen items measure somatic distress on a scale of 0 (not bothered), 1 (bothered a little), and 2 (bothered a lot). To meet criteria, at least three items must be answered with 2 (e.g. stomach pain, back pain, headaches, chest pain). In the current study, items were summed and the scoring indicated whether participants met or did not meet criteria for each disorder.

The Brief COPE is composed of 28 items measured on a four-point Likert scale ranging from 1 (I haven't been doing this at all) to 4 (I've been doing this a lot), with higher scores reflecting greater use of that coping style. Fourteen subscales, each comprised of two-items are inherent in the measure. In accordance with previous research (Ahnis et al., 2015, Elbelt et al., 2015; Figura, et al., 2015) the subscales of Venting, Denial, and Self-blame comprised avoidant coping; Emotional Support, Instrumental Support, and Religion, seeking support; Humor, Acceptance, and Positive Reframing, positive reframing; and lastly Planning and Active Coping composed active coping. Internal consistency analysis using the composition of the subscales as these four second order coping styles have yielded alpha coefficients between .38 and .80 (Ahnis et al., 2015; Figura, et al., 2015).

The BFMM is a 40-item scale of adjectives based on Goldberg's (1992) 100-item measure. Respondents are asked to rate themselves on how each of the positive and negative adjectives apply to them on a nine-point Likert scale from 1 (extremely inaccurate) to 9 (extremely accurate). Responses align with the Big-Five Personality Theory, yielding the scales of openness or intellect (openness to experience), conscientiousness, extraversion, agreeableness, 
and emotional stability. Higher scores reflect higher levels of the personality trait, where lower scores reflect the opposing trait (e.g. extraversion/ introversion, emotional stability/neuroticism). Saucier (1994) displayed acceptable to good internal consistency for the five-factors $(\alpha=.78$ $.83)$.

The TFEQ-R18 consists of three EE items measured on a four-point Likert scale from 1 (definitely false) to 4 (definitely true). The items are 'When I feel anxious, I find myself eating', 'When I feel blue, I often overeat', and 'When I feel lonely, I console myself by eating.' Item scores were summed with a highest possible score of 12 , with higher scores on this scale reflecting a greater degree of the inability to resist emotional cues. Previous research has indicated the internal consistency is good ( $\alpha=0.85$; Karlsson et al., 2000).

\section{Results}

The means, standard deviations, and the population sample are presented in Table 1 . The majority of participants were in the over 50 age group, accounting for $35.79 \%$ of the sample population. Relatively few participants were younger adults aged less than 29 years, accounting for $4.37 \%$.

Psychological Symptoms. Depressive, anxious, and somatic symptom results showed a low proportion of participants experiencing psychological distress, with 18\%, 16\%, and 32\%, respectively. In addition, 72 participants reported taking no medication (19.7\%), $81(22.1 \%)$ reported taking medication for a depressive disorder (including bipolar disorder), while 18 (4.9\%) were prescribed medication for an anxiety disorder (including panic disorder). Twentysix $(7.1 \%)$ participants reported taking medication for mixed anxiety and depression. The remaining 169 participants $(46.2 \%)$ were taking medication for a physical health issue. 
Coping style. The highest mean was for positive reframing style compared with avoidant and support coping. This indicates primary use of humour, acceptance, and positive reframing. Secondary use of avoidant coping was noted showing use of venting, denial, and self-blame. Notably, active coping has a lower range compared with the alternative coping styles, and thus is not comparable at the mean level.

Personality traits. The mean values of the personality traits showed the highest scores on agreeableness indicating compliant, cooperative, and trusting traits. Conversely, the lowest scores were on emotional stability indicating greater levels of hostility, anxiety, and depression, experience feeling vulnerability, self-conscious; and extraversion indicating greater levels of unassertive, quiet, and reserved traits.

\section{Data Analysis Overview}

The statistical software package SPSS-21 was used for data analysis. Descriptive analyses were conducted to identify the demographic characteristics and mean scores for the predictor variables and a hierarchical multiple regression was employed to address the research aim. For EE behaviour, age was entered at step 1, the variables of anxiety, depression, and somatization at the second step, coping variables at step 3, and the five personality traits were entered at step 4. To account for 21 missing cases pairwise-comparison analyses were used, as recommended by Tabachnick and Fidell (2013).

\section{Regression Analysis}

When age was controlled for at step two of the model, psychological distress accounted for significant variance in EE, $\Delta R^{2}=.037, \Delta F(4,340)=4.364, p<.01$, although, as displayed in Table 1, neither depression, anxiety, or somatization symptomology were significant individual predictors of EE behavior. At step 3 of the model coping styles accounted for an additional 4.6\% 
of unique variance in $\mathrm{EE}$, with avoidant coping, $\beta=-.26, p<.001$, being the only significant individual coping predictor of EE. Notably, the relationship between avoidant coping and EE was inverse to that hypothesized. When entered at step four in the regression equation, personality traits accounted for an additional $3.9 \%$ of variance in emotional eating, $\Delta R^{2}=.039$, $\Delta F(5,331)=2.94, p<.05$. As hypothesized, increased levels of extraversion predicted EE behavior, $\beta=.13, p<.05$, yet in contrast to that predicted, so did higher emotional stability, $\beta$ $=.14, p<.05$.

\section{Mediation Analysis}

As illustrated in Figure 1, it was predicted that avoidant coping would mediate the relationships of the personality traits of extraversion, agreeableness, and emotional stability, with EE. Specifically, emotional stability, extraversion, and agreeableness would each significantly relate to higher levels of avoidant coping and higher levels of EE. Although agreeableness was not identified as a significant predictor in the regression, this may have been due to other stronger predictors (e.g. emotional stability) masking the relationship between EE. As such, the planned mediation analysis was ruled appropriate and implemented in accordance with the recommendations of Baron and Kenny (1986). Bootstrapping was conducted using the process macro (Preacher \& Hayes, 2004).

Extraversion. As seen in Figure 2, extraversion was a significant predictor of EE, $b=.35$, $p>.001$, and remained significant after controlling for avoidant coping, $b=.03, p>.001$. Avoidant coping was a significant predictor of $\mathrm{EE}, b=-.16, p>.001$, and also related to extraversion, $b=-.03, p>.05$. Inspection of the $95 \%$ confidence intervals indicated that avoidant coping significantly partially mediated the relationship between extraversion and EE as the intervals did not contain zero. 
Agreeableness. Results showed agreeableness was a significant predictor of $\mathrm{EE}, b=-.03$, $p>.05$, and the relationship was reduced and became non-significant after controlling for avoidant coping, $b=.02, p=.08$. Avoidant coping was a significant predictor of $\mathrm{EE}, b=-1.59, p$ $>.001$, and related to agreeableness, $b=.05, p>.05$. Inspection of the $95 \%$ confidence intervals indicated that avoidant coping fully mediated the relationship between agreeableness and EE, displayed in Figure 3, as the intervals contained zero.

Emotional Stability. Emotional stability was a significant predictor of EE, $b=.04, p$ $>$.001. This relationship was reduced, although remained significant, after controlling for avoidant coping, $b=.03, p>.01$. Avoidant coping was a significant predictor of $\mathrm{EE}, b=-.13, p$ $>.001$, and also related to emotional stability, $b=-.09, p>.001$. The $95 \%$ confidence intervals indicated avoidant coping significantly partially mediated the relationship between emotional stability and EE, as the intervals did not contain zero.

\section{Discussion}

The present study aimed to explore the psychological factors impacting on continued obesity at one year post bariatric surgery, specifically, the relative importance of psychological symptomology (Hypothesis 1), coping skills (Hypothesis 2), and personality (Hypothesis 3) on EE behavior.

\section{Psychological Symptom Distress and Emotional Eating}

The non-significant relationship found between depressive, anxious, and somatic symptoms and EE was contradictory to previous studies of EE in populations of overweight or obese individuals (Karlsson et al., 2000; Konttinen et al., 2010; Stapleton et al., 2013). In the same way as alcohol has been found to act as a self-medicating attempt to relieve uncomfortable emotional and psychological states, the self-medicating hypothesis (SMH) proposes that 
uncomfortable emotional and psychological states trigger self-soothing behavior to alleviate symptom distress (Swendsen et al., 2000). This behavior is then negatively reinforced, increasingly the likelihood of self-soothing to reoccur when triggered (Swendsen et al.). We expected to see this same sequence in the results but whilst a number of individuals in the sample experienced negative psychological symptoms, this was not predictive of EE behavior. As mentioned, the majority of participants within the study did not have a clinical level of depressive, somatic or anxious symptomology as a group, thus negative emotional experiences, and those who did were not suffering severe enough symptoms for an effect. In total 125 participants $(34.1 \%)$ reported taking prescribed medication for depressive or anxious disorders and another $46.2 \%$ for other physical health concerns. The effect of this pharmacological support may have masked the relationship between this symptomology and EE.

There is an alternative: that the relationship between psychological distress and EE might be mediated by another variable or several. A number of authors have identified indirect pathways though introceptive awareness (van Strien et al., 2005), low levels of mindfulness (Pidgeon, Lacota, \& Champion, 2012), and difficulties identifying emotional states (Ouwens et al., 2009) may all play a role in EE. Individual characteristics, exercise motivation (Barberis et al. 2018; Costa et al. 2013); personality traits such as perfectionism (Costa, Hausenblas, Oliva, P. Et al., 2016; Cuzzocrea, Larcan, Lanzarone, 2012); the rule of parental control (Costa et al. 2016); the differences in clinical or non-clinical groups and the correlation between emotional eating, binge eating and obesity (Cuzzocrea et al. 2015) have all been proposed as potential variables influencing EE. The scope of this study could not account for all of these but are noted as important.

\section{Coping Style and Emotional Eating}


It was expected the use of avoidant coping for individuals who were 1-year post-bariatric surgery and still in an obese weight range would predict increased EE behavior, and positive reframing, active, and support coping styles would predict the opposite (Ahnis et al., 2015; Hörchner et al., 2002; Ryden et al., 2001). Participants within the study reported using little avoidance through venting, denial and self-blame, which subsequently was a negative predictor of emotional eating. And in contrast to the prediction, avoidant coping displayed an inverse relationship. Research within this domain is scant, with the small body of research demonstrating mixed findings. Figura and colleagues (2015) did not find a significant role of avoidant coping or any significant difference in coping style use when compared to positive reframing and seeking support. Similarly, Elbet et al (2015) found that avoidant coping was not predictive of engagement in physical exercise. As such, the relatively small evidence base in a bariatric population and as a predictor of emotional eating remains unclear.

\section{Personality Traits and Emotional Eating}

Personality variables were hypothesised to significantly predict EE behavior and this hypothesis was partially met, with a significant positive relationship between emotional stability and EE, and a significant positive relationship between extraversion and EE. Whilst the distribution of participants across genders in the present study was not sufficient to compare groups ( $95.1 \%$ were female), the findings indicated that for women, extraversion served as a risk factor for EE behaviour, consistent with previous research (Magee \& Heaven, 2011). The finding implicating high emotional stability (low neuroticism) as a positive predictor of EE was inconsistent with previous research that has found the inverse degree of association in Australian Bariatric populations (Gerlach et al., 2015; Jokela et al., 2013). It has been suggested, however, that the relationship between neuroticism and health outcomes, such as weight and EE, is more 
complex than frequently suggested (Chapman, Fiscella, Duberstein, Kawachi, \& Coletta, 2009). Chapman et al. (2009) found neuroticism was associated with lower obesity in men, and was unrelated to obesity in women. Brummett et al. (2006) suggest that for women, this trait is linked to maladaptive coping in health behaviours such as overeating and inactivity. Particularly, this trait may be reflective of adaptive health concerns, such as reducing in eating behaviour (Friedman, 2000).

Agreeableness has also demonstrated inconsistent findings within existing literature, with the current study indicating that this trait is likely not protective nor a risk for EE (Gerlach et al., 2015). Conscientiousness has previously been found to act as a protective factor (Gerlach et al.), although that relationship was not confirmed in the present study. In contrast, low but significant effect sizes have been demonstrated within the literature for weight gain in female bariatric populations for the personality trait of openness to experience (Armon et al., 2013; Gerlach et al.). Yet in the present sample, this finding was not replicated, indicating that akin to agreeableness and conscientiousness, openness to experience was not protective or at risk for individuals with continued obesity post-bariatric surgery.

\section{The Mediating Effect of Avoidant Coping}

It was hypothesised that extraversion, agreeableness, and emotional stability, would each be predictive of EE, mediated by an avoiding coping style. This hypothesis was supported for extraversion and emotional stability, with a partial medication effect observed. The relationship between agreeableness and EE was fully mediated by avoidant coping. In light of the nonsignificant direct relationship between agreeableness and emotional eating, the inclusion of avoidant coping may have shown an indirect relationship. 
Consistent with Lazarus' (1966) cognitive-phenomenological theory of psychological distress, the findings indicate that agreeableness led to choosing an avoidant style of coping when faced with aversive circumstances (Lazarus \& Folkman, 1984; Vollrath \& Torgersen, 2000). Individuals who are high on the agreeableness trait show a tendency towards being trusting of others, cooperative, and compliant (Costa \& McCrae, 1992). Subsequently, individuals with high trait agreeableness may engage in EE through an avoidant coping style. Similarly, extraversion was predictive of EE via avoidant coping in the current study, indicating the appraisal of situations and choice of coping style acting through this relationship (Lazarus \& Folkman, 1984; Vollrath \& Torgersen, 2000). In addition, according to Lazarus' (1966) model individuals with the trait of emotional stability, tend to use an avoidant coping style, and subsequently engage in EE behaviour (Ball et al., 2002; Costa \& McCrae, 1992). As such, it is important to consider that individuals who continue to be obese post-bariatric surgery may be experiencing the interplay between personality traits and coping skills (Montgomery \& Rupp, 2005). Thorough assessment of personality disorders and diagnosis should also be included.

\section{Theoretical Contributions and Application of Findings}

Individuals undertaking bariatric surgery often experience significant post-operative weight loss, however, a significant proportion of individuals do not experience this success. Weight loss failure has predominantly been attributed to a failure to address psychological factors impacting on overeating behaviour (Abilés et al., 2010). The current study aimed to investigate EE as an important risk and contributing factor for overweight and obesity. As such bariatric surgery treatments perhaps need to incorporate psychological strategies to assist people with managing this eating behaviour. 
The prominent findings of this study suggested of strong relationships between avoidant coping, extraversion, agreeableness, and EE behaviour within the sample population. This provides additional literature to the cognitive-phenomenological theory of psychological distress (Lazarus, 1966). Whilst this is beneficial support from a theoretical standpoint, practically this is also informative for health care providers in supporting bariatric patients. Although individuals may complete medical and psychological screening prior to receiving bariatric surgery, patients underlying etiology for obesity may not adequately be assessed (Abilés et al., 2010). Screening for personality vulnerabilities could allow for tailored complementary psychological services to promote weight-loss success. Applying such measures, or using similar processes to identify these factors, which can negatively affect patient outcomes, could have a significant impact both at an individual level and also more broadly in terms of reducing the healthcare costs associated with obesity. This recommendation should however, be taken in light of the limitations of the present study.

\section{Limitations and Recommendations for Future Research}

As it has previously been identified that there are potential differences in the psychological profile between genders, the findings are more applicable to women who are overweight and seeking bariatric surgery. The sample was confined to Australian and American citizens, thus generalisation to individuals from other countries would require replication for cross-cultural applicability. The assessment measures, coding, and operationalisation of constructs is an additional limitation within the study. Due to the overlap in depressive and somatic symptoms, which may be associated with obesity and bariatric surgery side-effects, measurement using the Patient Health Questionnaire may have yielded results which could have potentially over- or under-stated participants' level of symptomology (Hayden, Dixon, Dixon, \& 
O’Brien, 2010). As coding of depressive, anxious, and somatic symptomology was dichotomous, future research could ascertain the effect of a continuously measured variable. This may provide some understanding for the unexpected findings of psychological symptom distress, which is usually highly endorsed among obese individuals and those seeking treatment (Hayden et al.). Evers et al. (2011) also suggest that self-report measures of EE, such as the administered TFEQR18, may be reflective of an individual's attitude towards eating and emotions, rather than a measure of their food consumption after experiencing negative affective states.

Finally, psychological and personality disorder diagnosis were not made, and may have influenced the outcomes. Research has indicated that obese individuals seeking treatment have significantly higher rates of psychopathology compared to normal weight and non-treatment seeking control groups (Amhwani et al., 2013; Fitzgibbon, Stolley, \& Kirschenbaum, 1993). While the sample population here had lower rates of psychological symptom distress, maladaptive coping levels, and undesirable personality traits than expected, interpretation of the findings must consider the role of pharmacological support some of the participants were using, that may have also masked symptoms and distress levels.

\section{Summary and Conclusions}

It was the aim of this study to explore and describe the psychological characteristics of individuals who were at least one-year post bariatric surgery yet remained in the obese weight range. Individuals who experience continued obesity after bariatric surgery intervention are an underserviced population, who may require addition supports and tailored interventions that are matched with their needs. The negative relationship between avoidant coping and emotional stability as predictors of EE, and the positive relationship with extraversion highlighted in this 
study are two such areas. Avoidant coping was also found to mediate the relationships between emotional stability, extraversion, agreeableness and $\mathrm{EE}$ and also require further exploration. 


\section{References}

Abilés, V., Rodríguez-Ruiz, S., Abilés, J., Mellado, C., García, A., Pérez de la Cruz, A., \& Fernández-Santaella, M. C. (2010). Psychological characteristics of morbidly obese candidates for bariatric surgery. Obesity Surgery, 20, 161-167. doi: 10.1007/s11695-0089726-1.

Ahnis, A., Figura, A., Hofmann, T., Stengel, A., Elbelt, U., \& Klapp, B. F. (2015). Surgically and conservatively treated obese patients differ in psychological factors, regardless of body mass index or obesity-related co-morbidities: A comparison between groups and an analysis of predictors. PLoS One, 10. doi: 10.1371/journal.pone.0117460.

Amhwani, S., Boeka, A. G., Brown, J. D., Byrne, T. K., Budak, A. R., Sarwer, D. B., ... O’Neil, P. M. (2013). Socially desirable responding by bariatric surgery candidates during psychological assessment. Surgery for Obesity and Related Diseases, 9, 300-305. doi: 10.1016/j.soard.2011.06.019.

Andersen, J.R., Aasprang, A., Bergsholm, P., Sletteskog, N., Vage, V., \& Natvig, G.K. (2010). Anxiety and depression in association with morbid obesity: changes with improved physical health after duodenal switch. Health and Quality of Life Outcomes, 8, 52-58. doi: $10.1186 / 1477-7525-8-52$.

Armon, G., Melamed, S., Shirom, A., Shapira, I., \& Berliner, S. (2013). Personality traits and body weight measures: concurrent and across time associations. European Journal of Personality, 27, 398-408. doi: 10.1002/per.1902.

Backstrom, M., \& Bjorklund, F. (2013). Social desirability in personality inventories: Symptoms, diagnosis and prescribed cure. Scandinavian Journal of Psychology, 54, 152-159. doi: 10.1111/sjop.12015. 
Ball, S., Smolin, J., \& Shekhar, A. (2002). A psychobiological approach to personality: examination within anxious outpatients. Journal of Psychiatric Research, 36, 97-103. doi: 10.1016/S0022-3956(01)00054-1.

Barberis N, Costa S, Cuzzocrea F, Quattropani M.C. (2018). Trait EI in the relationship between needs fulfilment and symptoms and attitudes associated with EDs. Mental Health \& Prevention, 10, 560-55 https://doi.org/10.1016/j.mhp.2018.01.003

Baron, R. M., \& Kenny, D. A. (1986). The moderator-mediator variable distinction in social psychological research: Conceptual, strategic, and statistical considerations. Journal of personality and social psychology, 51, 1173-1182. doi: 10.1037//0022-3514.51.6.1173

Beck, A. T., Rush, A. J., Shaw, B. F., \& Emery, G. (1979). Cognitive therapy of depression. New York, N.Y.: The Gilford Press.

Blair, E.H., Wing, R.R., \& Wald, A. (1991). The effects of laboratory stressors on glycemic control and gastrointestinal transit-time. Psychosomatic Medicine, 53,133-143. doi: 10.1016/j.tem.2009.10.004

Bocchieri, L. E., Meana, M., \& Fisher, B. L. (2002). A review of psychosocial outcomes of surgery for morbid obesity. Journal of Psychosomatic Research, 52, 155-165. doi: 10.1016/S0022-3999(01)00241-0.

Bruinsma, K., \& Taren, D. (1999). Chocolate: Food or drug? Journal of the American Dietetic Association, 99, 1249-1256. doi: 10.1016/S0002-8223(99)00307-7.

Brummett, B. H., Babyak, M. A., Williams, R. B., Barefoot, J. C., Costa, P. T., \& Siegler, I. C. (2006). NEO personality domains and gender predict levels and trends in body mass index over 14 years during midlife. Journal of Research in Personality, 40, 222-236. doi: 10.1016/j.jrp.2004.12.002 
Burgmer, R., Petersen, I., Burgmer, M., de Zwaan, M., Wolf, A.M., \& Herpertz, S. (2007). Psychological outcome two years after restrictive bariatric surgery. Obesity Surgery, 17, 785-791. doi: 10.1007/s11695-007-9144-9.

Busetto, L., Segato, G., De Luca, M., De Marchi, F., Foletto, M., Vianello, M., ... Enzi, G. (2005). Weight loss and postoperative complications in morbidly obese patients with binge eating disorder treated by laparoscopic adjustable gastric banding. Obesity Surgery, 15, 195-201. doi: 10.1381/0960892053268327.

Byrne, S. M. (2002). Psychological aspects of weight maintenance and relapse in obesity. Journal of Psychosomatic Research. 53, 1029-1036. doi: 10.1016/S0022-3999(02)004877

Carver, C. S. (1997). You want to measure coping but your protocol's too long: consider the Brief COPE. International Journal of Behavioural Medicine, 4, 92-100. doi.org/10.1207/s15327558ijbm0401_6

Carver, C. S., Scheier, M., \& Weintraub, J. (1989). Assessing coping strategies: A theoretically based approach. Journal of Personality and Social Psychology, 56, 267-283. doi: 10.1037/0022-3514.56.2.267.

Chapman, B. P., Fiscella, K., Duberstein, P., Kawachi, I., \& Coletta, M. (2009). Can the influence of childhood socioeconomic status on men's and women's adult body mass be explained by adult socioeconomic status or personality? Findings from a national sample. Health Psychology, 28, 419-427. doi: 10.1037/a0015212.

Costa S, Hausenblas H, Oliva P, Cuzzocrea F, Larcan R. (2013). The role of age, gender, mood states and exercise frequency on exercise dependence. Journal of Behavioral Addictions, 2(4), 1-8. http://dx.doi.org/10.1556/JBA.2.2013.014 
Costa, S., Hausenblas, H.A., Oliva, P., Cuzzocrea, F., Larcan, R. (2016). Maladaptive Perfectionism as mediator among psychological control, eating disorders, and exercise dependence symptoms in habitual exerciser. Journal of Behavioral Addictions, 5(1), 7789. http://dx.doi.org/10.1556/2006.5.2016.004

Costa, P. T., \& McRae, R. R. (1992). Revised NEO Personality Inventory (NEO-PI-R) and NEO Five-Factor Inventory (NEO-FFI) professional manual. Odessa, Florida: Psychological Assessment Resources, Inc.

Cuzzocrea F., Costa S., Larcan R., Toffle M.E. (2015). Differences between adolescents exhibiting moderate binging and non-binging eating behaviors. SpringerPlus, 4(1):593, 110. http://dx.doi.org/10.1186/s40064-015-1372-1

Cuzzocrea F, Larcan R, Lanzarone C. (2012). Gender differences, Personality and eating behaviors in non-clinical adolescents. Eating and Weight Disorders. Studies on Anorexia Bulimia Obesity, 17(4), 282-289.

de Zwaan, M., Enderle, J., Wagner, S., Mühlhans, B., Ditzen, B., Gefeller, O., ... Müller, A. (2011). Anxiety and depression in bariatric surgery patients: A prospective, follow-up study using structured clinical interviews. Journal of Affective Disorders, 133, 61-68. doi: 10.1016/j.jad.2011.03.025.

Dixon, J. B., O'Brien, P. E., Playfair, J., Chapman, L., Schachter, L. M., Skinner, S., ... Anderson, M. (2008). Adjustable gastric banding and conventional therapy for type 2 diabetes: a randomized controlled trial. Journal of the American Medical Association, 299, 316-323. doi: 10.1001/jama.299.3.316.

Elbelt, U., Ahnis, A., Riedl, A., Burkert, S., Schuetz, T., Ordemann, J., .. Klapp, B. F. (2015). Associations of physical activity with depressiveness and coping in subjects with high- 
grade obesity aiming at bariatric surgery: a cross-sectional study. Japanese Society of Psychosomatic Medicine, 9, doi: 10.1186/s13030-015-0042-4.

Evers, C., de Ridder, D.T., \& Adriaanse, M.A. (2011). Assessing yourself as an emotional eater: Mission impossible? Appetite, 57, 536. doi: 10.1016/j.appet.2011.05.005

Figura, A., Ahnis, A., Stengel, A., Hofmann, T., Elbelt, U., Ordemann, J., \& Rose, M. (2015). Determinants of Weight Loss following Laparoscopic Sleeve Gastrectomy: The Role of Psychological Burden, Coping Style, and Motivation to Undergo Surgery. Journal of Obesity, 2015. doi: 10.1155/2015/626010.

Fischer, S., Chen, E., Katterman, S., Roerhig, M., Bochierri-Ricciardi, L., Munoz, D.,...le Grange, D. (2007). Emotional eating in a morbidly obese bariatric surgery-seeking population. Obesity Surgery, 17, 778-784. doi: 10.1007/s11695-007-9143.

Friedman, H. S. (2000). Long-term relations of personality and health: Dynamisms, mechanisms, tropisms. Journal of Personality, 68(6), 1089-1107. doi: 10.1111/14676494.00127

Fitzgibbon, M.L., Stolley, M.R., \& Kirschenbaum, D.S. (1993). Obese people who seek treatment have different characteristics than those who do not seek treatment. Health Psychology, 12, 342-345. doi: 10.1037/0278-6133.12.5.342.

Friedman, H. S. (2000). Long-term relations of personality and health: Dynamisms, mechanisms, tropisms. Journal of Personality, 68(6), 1089-1107. doi: 10.1111/1467-6494.00127

Ganley, R.M. (1989). Emotion and eating in obesity: A review of the literature. International Journal of Eating Disorders, 8, 343-361. doi: 10.1002/1098-108. 
Geliebter, A., \& Aversa, A. (2003). Emotional eating in overweight, normal weight, and underweight individuals. Eating Behaviours, 3, 341-347. doi: 10.1016/S14710153(02)00100-9

Gerlach, G., Herpertz, S., \& Loeber, S. (2015). Personality traits and obesity: a systematic review. Obesity Reviews, 16, 32-63. doi: 10.1111/obr.12235.

Glinski, J., Wetzler, S., \& Goodman, E. (2001). The psychology of gastric bypass surgery. Obesity Surgery, 11, 581-8. doi: 10.1381/09608920160557057.

Goldberg, L. R. (1992). The development of markers for the big-five factor structure. Psychological Assessment, 4, 26-42. doi: 10.1037/1040-3590.4.1.26.

Goodspeed Grant, P. (2008). Food for the Soul: Social and Emotional Origins of Comfort Eating in the Morbidly Obese in Psychological Responses to Eating Disorders and Obesity. London, England: Wiley and Sons.

Goossens, L., Braet, C., Van Vlierberghe, L., Mels, S. (2009). Loss of control over eating in overweight youngsters: The role of anxiety, depression, and emotional eating. European Eating Disorders Review, 17, 68-78. doi: 10.1002/erv.892

Gregory D. M., Temple Newhook J., \& Twells L. K. (2013). Patients’ perceptions of waiting for bariatric surgery: A qualitative study. International Journal for Equity in Health, 12, 86. doi: $10.1186 / 1475-9276-12-86$.

Hayden, M., Dixon, J., Dixon, M., \& O'Brien, P. (2010). Confirmatory factor analysis of the Beck Depression Inventory in obese individuals seeking surgery. Obesity Surgery, 20, 432-439. doi: 10.1007/s11695-009-9977-5.

Herman, C. P., \& Mack, D. (1975). Restrained and unrestrained eating. Journal of Personality, 43, 647-660. 
Herman, C. P., \& Polivy, J. (1980). Restrained eating. In A.B. Stunkard (Ed.). Obesity, 208-225. Saunders, Philadelphia.

Herpertz, S., Kielmann, R., Wolf, A. M., Hebebrand, J., \& Senf, W. (2004). Do psychosocial variables predict weight loss or mental health after obesity surgery? A systematic review. Obesity Research, 10, 1554-1569. doi: 10.1038/oby.2004.195.

Hörchner, R., Tuinebreijer, W. E., Kelder, H., \& van Urk, E. (2002). Coping behaviour and loneliness among obese patients. Obesity Surgery, 12, 864-868. doi: 10.1381/096089202320995718.

Jokela, M., Hintsanen, M., Hakulinen, C., Batty, G. D., Nabi, H., Singh-Manoux, A., \& Kivimäki, M. (2013). Association of personality with the development and persistence of obesity: a meta-analysis based on individual-participant data. Obesity Reviews, 14, 315323. doi: 10.1111/obr.12007

Kaplan, H. I., \& Kaplan, H. S. (1957). The psychosomatic concept of obesity. The Journal of Nervous and Mental Disease, 125, 181-200. Retrieved from http://europepmc.org

Karlsson, J., Persson, L., Sjöström,, L., \& Sullivan, M. (2000). Psychometric properties and factor structure of the Three-Factor Eating Questionnaire (TFEQ) in obese men and women. Results from the Swedish Obese Study (SOS) study. International of Obesity and Related Metabolic Disorder, 24,1715-1725. doi: 10.1038/sj.ijo.0801442

Karlsson, J., Taft, C., Rydén, A., Sjöström, L., \& Sullivan, M. (2007). Ten-year trends in healthrelated quality of life after surgical and conventional treatment for severe obesity: the SOS intervention study. International Journal of Obesity 31, 1248-1261. doi: 10.1038/sj.ijo.0803573. 
Konttinen, H., Mannisto, S., Sarlio-Lahteenkorva, S., Silventoinen, K., \& Haukkala, A. (2010). Emotional eating, depressive symptoms, and self-reported food consumption: A population-based study. Appetite, 54, 437-479. doi: 10.1016/j.appet.2010.01.014.

Kroenke, K., Spitzer, R. L., Williams, J. B. W., \& Löwe, B. (2010). The Patient Health Questionnaire somatic, anxiety, and depressive Symptom Scales: a systematic review. General Hospital Psychiatry, 32, 345-359. doi: 10.1016/j.genhosppsych.2010.03.006

Lanzarone C, Cuzzocrea F, Larcan R, Bongiorno A, Minì V. (2014). Effectiveness of Cognitive Behavioural Psychotherapy with Pharmacological support in Binge Eating Disorder: A differential research. British Journal of Medical Practitioners, 7(3), 724-731

Lazarus, R. S. (1966). Psychological Stress and the Coping Process. New York: McGraw-Hill.

Lazarus, R. S., \& Folkman, S. (1984). Stress, appraisal and coping. New York: Springer.

Macht, M. \& Mueller, J. (2007). Immediate effects of chocolate on experimentally induced mood states. Appetite, 49, 667-674. doi: 10.1016/j.appet.2007.05.004.

Magee, C. A. \& Heaven, P. C. L. (2011). Big five personality factors, obesity and 2-year weight gain in Australian adults. Journal of Research in Personality, 45, 332-335. doi: 10.1016/j.jrp.2011.02.009.

Montgomery, C., \& Rupp, A. A. (2005). A meta-analysis for exploring the diverse causes and effects of stress in teachers. Canadian Journal of Education, 28, 458-486. doi: $10.2307 / 4126479$.

Mosher, C. E., Prelow, H. M., Chen, W. W., \& Yackel, M. E. (2006). Coping and social support as mediators of the relation of optimism to depressive symptoms among black college students. Journal of Black Psychology, 32, 72-86. doi: 10.1177/0095798405282110. 
Nguyen-Rodrigues, S. T., Unger, J. B., \& Spruijt-Metz, D. (2009). Psychological determinants of emotional eating in adolescence. Eating Disorders, 17, 211-224. doi: 10.1080/10640260902848543.

Ouwens, M.A., van Strien, T., \& van Leeuwe, J.F.J. (2009). Possible pathways between depression, emotional and external eating: A structural equation model. Appetite, 53, 245-248. doi: 10.1016/j.appet.2009.06.001.

Pidgeon, A., Lacota, K., \& Champion, J. (2012). The moderating effects of mindfulness on psychological distress and emotional eating behaviour. Australian Psychologist, 48, 262269. doi: 10.1111/j.1742-9544.2012.00091

Preacher, K. J., \& Hayes, A. F. (2008). Asymptotic and resampling strategies for assessing and comparing indirect effects in multiple mediator models. Behavior research methods, 40, 879-891. doi:10.3758/brm.40.3.879

Provencher, V., Bégin, C., Gagnon-Girouard, M., Tremblay, A., Boivin, S., \& Lemieux, S. (2008). Personality traits in overweight and obese women: associations with BMI and eating behaviors. Eating Behaviors, 9(3), 294-302. doi: 10.1016/j.eatbeh.2007.10.004.

Raspopow, K., Matheson, K., Abizaid, A., \& Anisman, H. (2013). Unsupportive social interactions influence emotional eating behaviors. The role of coping styles as mediators. Appetite, 62, 143-149. doi: 10.1016/j.appet.2012.11.031.

Rydén, A., Karlsson, J., Persson, L. O., Sjöström, L., Taft, C., \& Sullivan, M. (2001). Obesity-related coping and distress and relationship to treatment preference. The British Journal of Clinical Psychology, 40,177-188. doi: 10.1348/014466501163625.

Saucier, G. (1994). Mini-Markers: A brief version of Goldberg's unipolar big-five markers. Journal of Personality Assessment, 63, 506-516. doi: 10.1207/s15327752jpa6303_8 
Sjöström, C. D., Lissner, L., Wedel, H., \& Sjöström, L. (1999). Reduction in incidence of diabetes, hypertension and lipid disturbances after intentional weight loss induced by bariatric surgery: the SOS intervention study. Obesity Research, 7, 477-484. doi: 10.1002/j.1550-8528.1999.tb00436.x.

Swendsen, J. D., Tennen, H., Carney, M. A., Affleck, G., Willard, A., \& Hromi, A. (2000). Mood and alcohol consumption: an experience sampling test of the self-medication hypothesis. Journal of Abnormal Psychology, 109, 198-204. doi: 10.1037//0021843X.109.2.198.

Tabachnick, B.G., \& Fidell, L.S. (2013). Using Multivariate Statistics $\left(6^{\text {th }}\right.$ ed.). Boston: Pearson Education.

van Strien, T., Engels, R.C., Van Leeuwe, \& Snoeck, H.M. (2005). The Stice model of overeating: tests in clinical and non-clinical samples. Appetite, 45, 305-213. doi: 10.1016/j.appet.2005.08.004.

Vollrath, M., \& Torgersen, S. (2000). Personality types and coping. Personality and Individual Differences, 29, 367-378. doi: 10.1016/S0191-8869(99)00199-3.

Wing, R. R., Blair, E. H., Epstein, L. H., \& McDermott, M. D. (1990). Psychological stress and glucose metabolism in obese and normal-weight subjects: A possible mechanism for differences in stress-induced eating. Health Psychology, 9, 693-700. doi: 10.1037/02786133.9.6.693. 
Figures
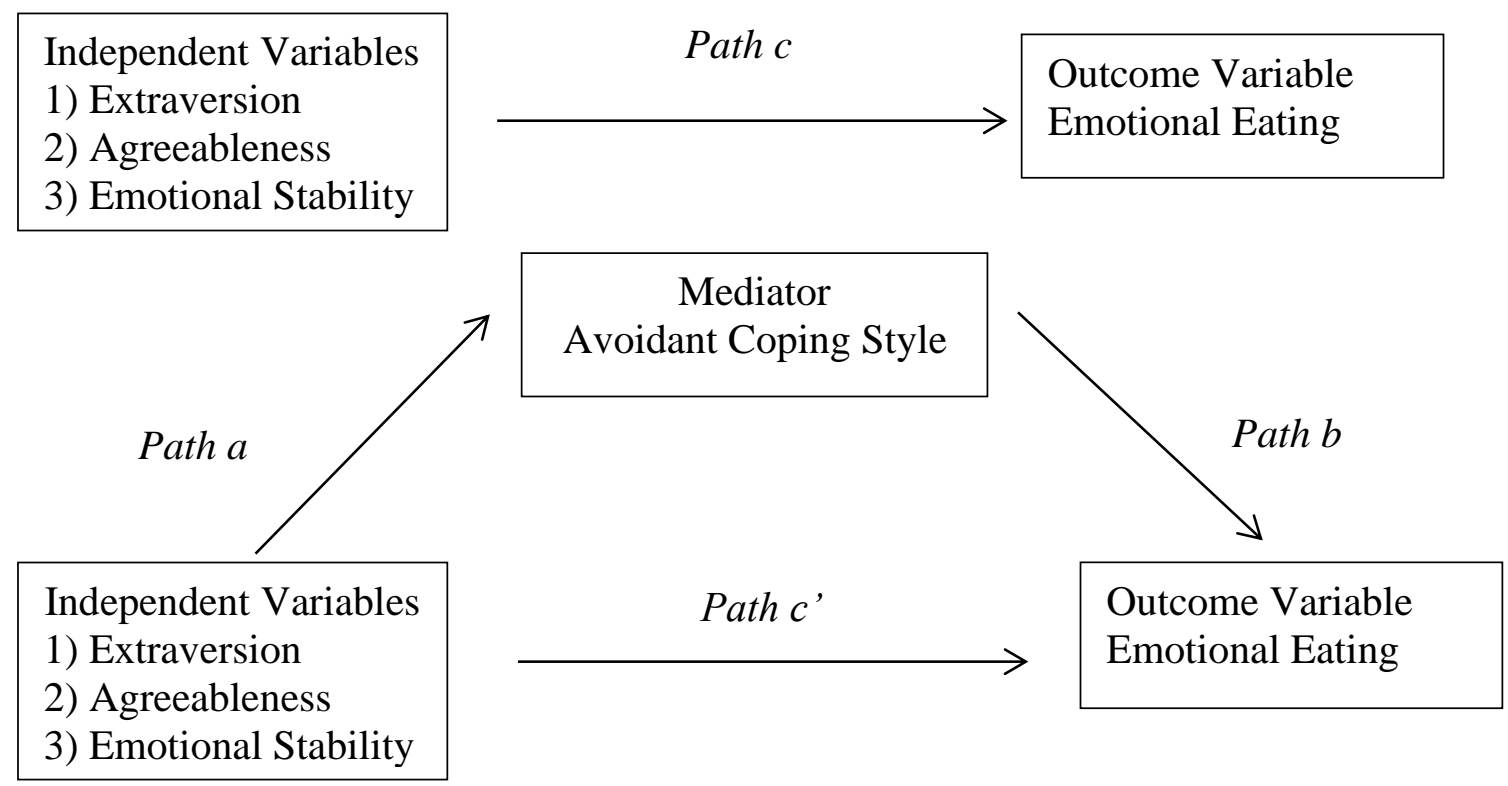

Figure 1. Model linking personality traits to emotional eating through avoidant coping style.

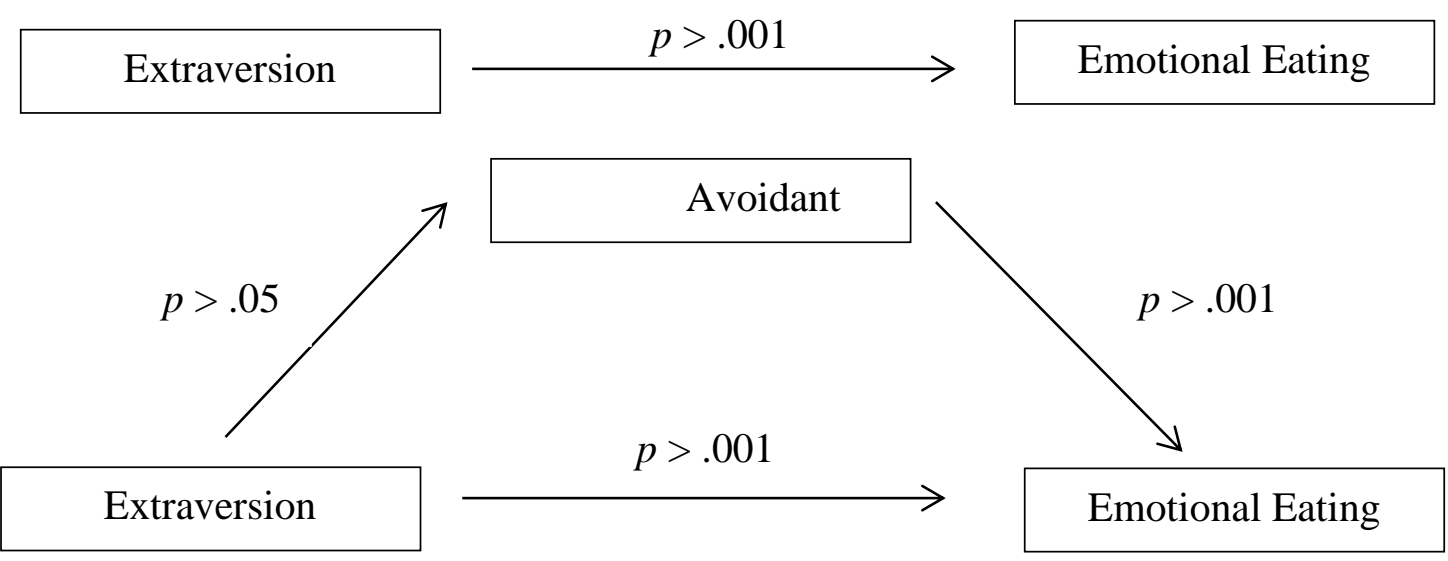

Figure 2. The relationship between extraversion and emotional eating, with confirmed partial mediation by avoidant coping. N.B: The top portion of the figure 


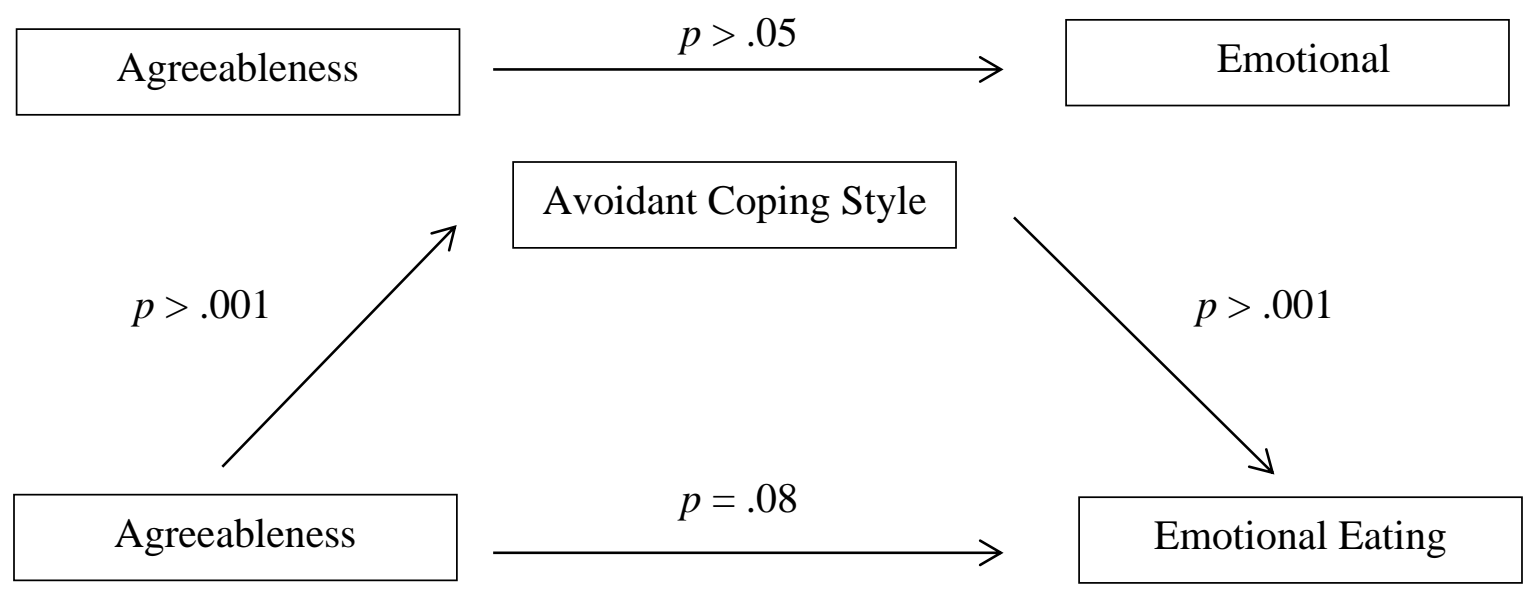

Figure 3. The relationship between agreeableness and emotional eating, with confirmed partial mediation by avoidant coping.

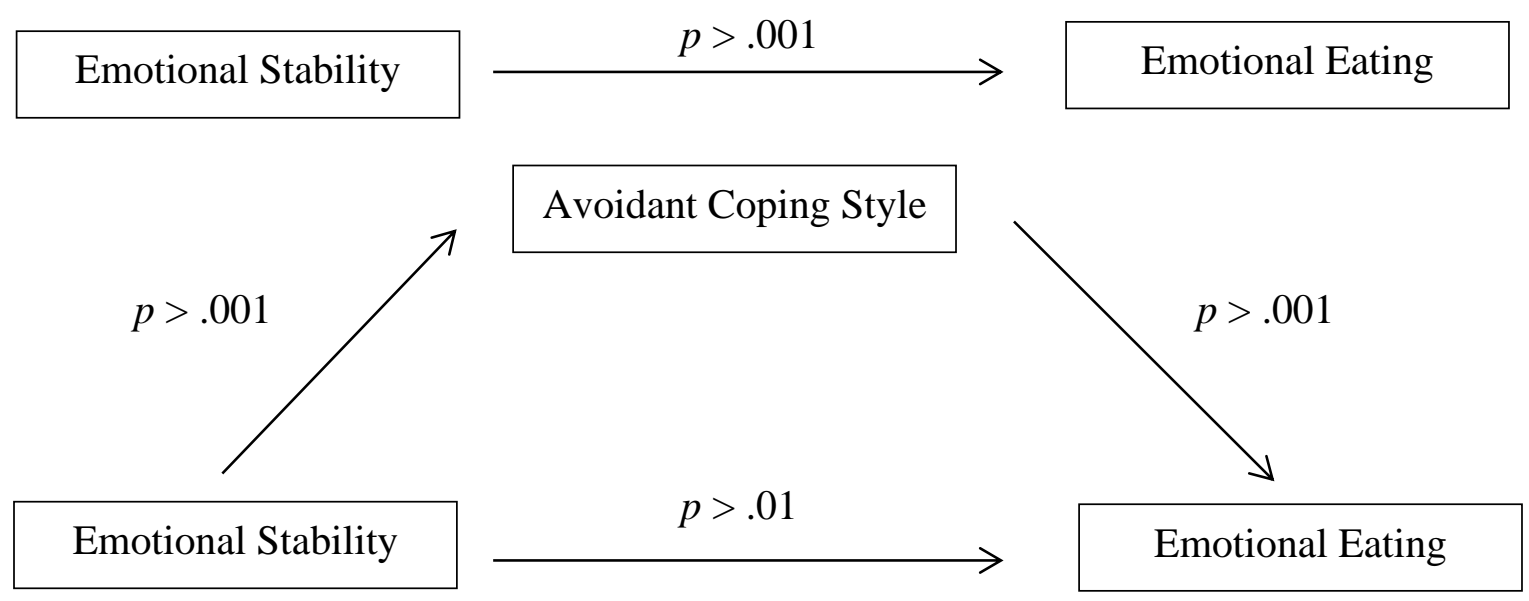

Figure 4. The relationship between emotional stability and emotional eating, with confirmed partial mediation by avoidant coping. 
Tables

Table 1

Hierarchical Regression Analysis for Variables Predicting Emotional Eating $(N=366)$

\begin{tabular}{|c|c|c|c|c|c|}
\hline Predictor & $\Delta R^{2}$ & $\beta$ & B & SEB & $95 \% \mathrm{CI}$ \\
\hline Step1 & .000 & & & & \\
\hline Age & & .05 & .01 & .01 & {$[-.01, .03]$} \\
\hline Step 2 & $.037 * *$ & & & & \\
\hline Age & & .02 & .00 & .01 & {$[-.02, .03]$} \\
\hline Depression & & -.12 & -.62 & .33 & {$[-1.27, .38]$} \\
\hline Anxiety & & -.06 & -.32 & .34 & {$[-.99, .35]$} \\
\hline Somatisation & & -.08 & -.36 & .25 & {$[-.85, .13]$} \\
\hline Step 3 & $.046^{* * *}$ & & & & \\
\hline Age & & -.01 & -.00 & .01 & {$[-.02, .02]$} \\
\hline Depression & & -.05 & -.26 & .34 & {$[-.93, .40]$} \\
\hline Anxiety & & -.03 & -.16 & .34 & {$[-.82, .51]$} \\
\hline Somatisation & & -.05 & -.21 & .25 & {$[-.70, .28]$} \\
\hline Avoidant Coping & & $-.26 * * *$ & -.17 & .04 & {$[-.26,-.09]$} \\
\hline Seeking Support & & -.03 & -.01 & .03 & {$[-.08, .05]$} \\
\hline Positive Reframing & & .07 & .04 & .04 & {$[-.03, .12]$} \\
\hline Active Coping & & .06 & .05 & .05 & {$[-.05, .15]$} \\
\hline Step 4 & $.039 *$ & & & & \\
\hline Age & & -.01 & -.00 & .01 & {$[-.02, .02]$} \\
\hline Depression & & -.03 & -.18 & .34 & {$[-.84, .48]$} \\
\hline Anxiety & & .02 & .09 & .34 & {$[-.58, .76]$} \\
\hline Somatisation & & -.02 & -.09 & .25 & {$[-.58, .40]$} \\
\hline Avoidant Coping & & $-.18 * *$ & -.12 & .05 & {$[-.21,-.03]$} \\
\hline Seeking Support & & -.06 & -.03 & .03 & {$[-.10, .03]$} \\
\hline Positive Reframing & & .02 & .01 & .04 & {$[-.06, .09]$} \\
\hline Active Coping & & .03 & .02 & .05 & {$[-.08, .12]$} \\
\hline Extraversion & & $.13^{*}$ & .02 & .01 & {$[.00, .04]$} \\
\hline Agreeableness & & .01 & .00 & .01 & {$[-.03, .03]$} \\
\hline Conscientiousness & & .00 & .00 & .01 & {$[-.02, .02]$} \\
\hline Emotional Stability & & $.14^{*}$ & .02 & .01 & {$[.00,-.05]$} \\
\hline Openness & & .08 & .02 & .01 & {$[-.01, .04]$} \\
\hline Total $R^{2}=.125^{* * *}$ & & & & & \\
\hline
\end{tabular}

Note: $* \mathrm{p}<.05, * * \mathrm{p}<.01, * * * \mathrm{p}<.001$. 